BEHIND THE NEWS

\section{Exit interview with Dr. Alan}

\section{Bernstein}

$\mathrm{H}$

istory will probably record the move as the crucible upon which the grand experiment called the Canadian Institutes of Health Research (CIHR) ultimately turned.

In response to recommendations from a blue-ribbon International Review Panel, (CMAJ 2006;175 [8]: 857-8), CIHR's governing council recently agreed to devolve authority to divide its financial pie to a newly minted Research and Knowledge Translation Committee comprised primarily of the scientific directors of the agency's I3 so-called "virtual" institutes.

Was it, as some believe, a coup by the old boy biomedical network who were disgruntled by declining success rates (now at roughly $16.3 \%$ ) in open grants competitions and the amount of monies that the CIHR was pouring into the 3 other "pillars" of research (clinical, population health, and health services and systems research), or into strategic, multidisciplinary, interdisciplinary and collaborative initiatives in areas of national health need?

Is it the prelude, as others believe, to a transformation of CIHR into the Canadian equivalent of the US National
Institutes of Health, in which monies are now divvied up among 28 thematic institutes essentially operating as independent fiefdoms, running separate grant competitions, while in constant war with one another for a larger share of the overall pot?

Or will the new decision-making body craft a uniquely Canadian response that divides the pie in such a way that all are satisfied and the CIHR still manages to honour its legislative mandate to significantly expand the ambit beyond basic biomedical science to include the other 3 pillars of research?

Is it even possible to satisfy everyone in an era in which application demand skyrockets each year because of explosive growth in the university research community prompted by multibillion dollar investments made through other federal programs like the Canada Foundation for Innovation, Genome Canada or the Canada Research Chairs?

In a candid discussion about his 7year tenure at the helm, outgoing CIHR President Dr. Alan Bernstein, who's resigning his post effective Oct. 3I (CMAJ 2007:177[3]:24I), rejected the notion that a coup has been quietly staged on his watch.

But Bernstein said there's little doubt that CIHR, which now annually dispenses a whopping $\$ 828$ million, stands poised at a bifurcation point, particularly with respect to the role

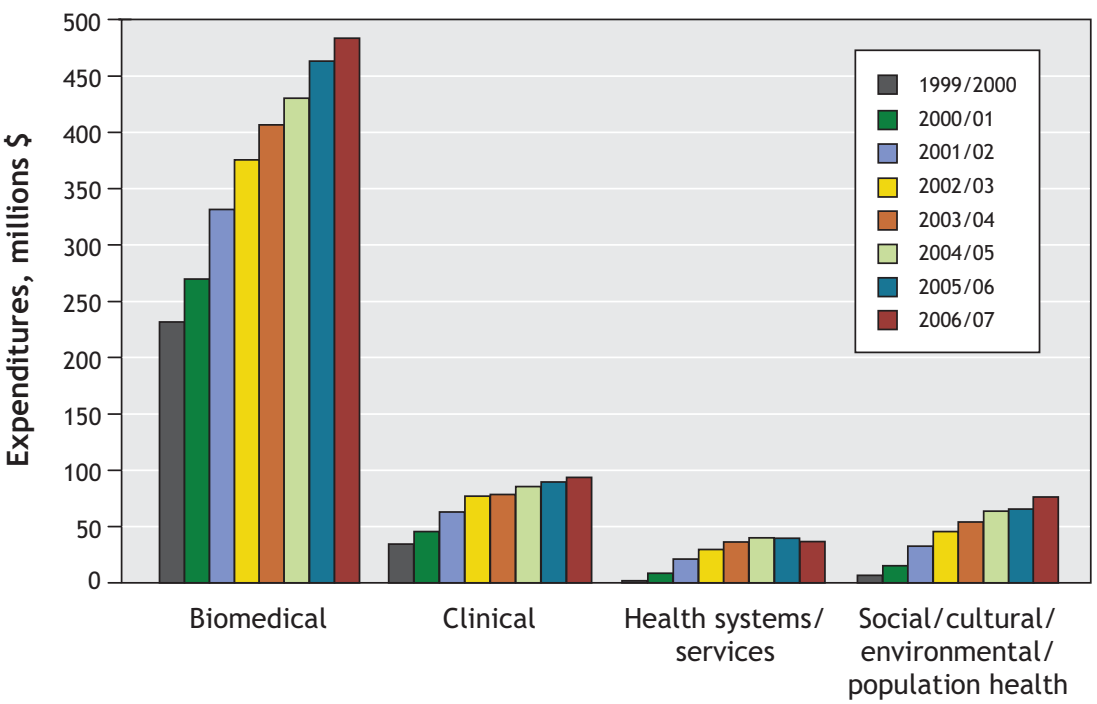

Figure 1: Total CIHR grants and awards, by pillar, in the 7 years of agency operation. Source: CIHR. and functions of its 13 thematic institutes and scientific leaders.

"Their functions are still very much a work in progress and where that will end up I,2,3,5 years from now, I don't know," Bernstein said, adding that there is a "tension" between 2 futures. "One extreme is that the Institutes are silos, [in which] they only worry about their own institute mandates and their own institute budgets. The other extreme is the institutes are CIHR, that they are the entire organization. They represent the organization. They control 100\% of the budget. Where the sweet spot is between those 2 extremes, I think, will probably vary with time and personalities. But I think it's very much part of the maturing of the organization."

To evolve down a US-style path in which the CIHR's institutes operate as separate organizations "would be a huge mistake," Bernstein added. "That would then be going down the road, in my judgment, of creating I4 different organizations."

The Research and Knowledge Translation Committee, Bernstein argued, is essentially an attempt to force the institutes themselves to "take ownership of the entire organization. I think the SDs [scientific directors] are up to the task."

The I3 scientific directors, along with CIHR's president, vice-president of research, vice-president of knowledge translation, executive vice-president, director of ethics and chief financial officer will sit on the I9-member committee. Its role, Bernstein said, is "to make the strategic decisions about how much should go into each of these different funding programs, whether it's major operating grants programs or strategic initiatives, commercialization, knowledge translation, ethics, international, you name it."

CIHR's governing council was persuaded of the merits of devolving its authority to make financial decisions by the recommendations of the 27member International Review Panel, chaired by Oxford University Regius Professor of Medicine Dr. John Bell. The panel had urged more "academic leadership" in divvying up the pie.

"I think what the IRP [International Review Panel] was saying, and I agree with them, was look, the great strength 
of CIHR was these virtual institutes and the energy that was unleashed when the institutes were created," Bernstein said. "Take advantage of that. Harness that energy and use the science and the scientists and the researchers to provide strategic advice as to where CIHR should be going, not just for their own institutes but across the organization."

As the US has discovered, such an approach risks a situation in which larger, biomedical disciplines like neurosurgery, gobble up an ever-larger chunk of available monies at the expense of smaller disciplines in the other 3 pillars. Under such a regime, there's also less incentive to invest in multidisciplinary or interdisciplinary research and few mechanisms or programs to promote such work.

But Bernstein says the composition of the committee, particularly the fact that it includes scientific directors representing institutes in the other 3 pillars, mitigates against such risks.

"Roughly half of the SDs come from pillars 3 and 4," Bernstein argues. "There's a pretty balanced composition on our RKTC [Research and Knowledge Translation Committee]."

Moreover, all of the institutes have come forward with initiatives that cross the pillars, Bernstein said, citing a $\$ 4.5$ million Institute of Cancer Research initiative to promote palliative care research as an example of the sort of cross-cutting programs that can now be found across CIHR.

Still, the mix of CIHR investment among the 4 pillars (Figure I) has long been a contentious issue, although expansion of the ambit of research was the rationale for the agency's creation from the ashes of the predecessor Medical Research Council of Canada, which had been receiving roughly $\$ 250$ million per year from the federal government.

Health and clinical researchers have long contended CIHR has invested too slowly in non-biomedical disciplines. But Bernstein says the slow growth rate in those areas was largely a function of a lack of critical mass within those sectors during the agency's formative years.

"Not to be defensive about the record but I think you have to look at it, not as a snapshot, but as a trajectory. And I think that the trajectory is the most important thing here. You can't build up an area

\section{Box 1: Bernstein's Top 5}

Outgoing Canadian Institutes of Health Research president Alan Bernstein pegs his top 5 accomplishments at the agency helm as being:

- Transformative Change: CIHR now funds research across the complete spectrum of health and disease. The dollar value of research going to health services and population health research has increased between 15- and 20-fold. Over 50 new multidisciplinary teams have been funded to encourage a problem-solving approach to research. The 13 virtual Institutes have outstanding Scientific Directors, Institute Advisory Boards, strategic plans and initiatives, and a sustainable appointments process well in place.

- Partnerships and Collaboration: Almost all partnerships are now aligned with articulated strategic goals of CIHR's Institutes. The monetary value of partnerships has doubled since 2000.

- Next Generation of Researchers: The launch of the Strategic Training Initiative in Health Research and the creation of 90 new Research Training Centres in 2002 essentially doubles the number of trainees funded by CIHR. The salary awards program was reconfigured to emphasize support for New Investigators, thus increasing the number funded by more than $50 \%$.

- Resources: CIHR’s budget has increased from $\$ 360$ million to over $\$ 1.0$ billion, including indirect costs and 700 Canada Research Chairs in health.

- Knowledge Translation: The necessary groundwork to complement the second half of CIHR's parliamentary mandate - the translation of research into improved health, a stronger health care system, and new products and services - is now in place.

simply by spending money on it. Definitely, money helps. But it needs developing capacity and commitment locally."

"We are also about excellence, so I'm not simply going to put more money into an area, just to make the data look better."

Bernstein pegged the current mix among the 4 pillars as roughly $70 \%$ basic biomedical, I4\% clinical, II\% population health and $5 \%$ health services and systems.

He added the mix is also invariably affected by the differing nature and cost of different types of research (biomedical grants are on average \$150 ooo per year as compared to \$III ooo per year in other pillars), as well as by demand, which in turn is often driven by decisions at the local university or hospital level.

A successful bid for a Canada Foundation for Innovation infrastructure grant within a discipline, or the creation of a new research chair by a university, invariably increases application pressure in CIHR competitions, Bernstein notes. "Within that, if you actually look across where universities and hospitals in Canada are investing, they are selectively investing in themes I and 2."

It points to the need for a "more coherent approach to the funding of science in this country," in which the level of granting council budgets can accommo- date the pressures created by infrastructure and personnel investments, Bernstein argued. "There's a need for better coordination and alignment" between the investments of federal agencies, provinces and other research partners.

Bernstein also argued CIHR investments have been instrumental in the move toward more "evidence-based approaches" within the health care system, like the use of wait-times benchmarks, and that Canada stands poised to make a rash of breakthroughs in health, clinical and interdisciplinary research in the next few decades (Box I).

"I truly believe we have truly built an entirely new national funding organization, that is problem-based, strategic, inclusive of the 4 themes, that spans research to knowledge translation, that has become the model for the world," Bernstein said. "The impact is not totally going to be felt today. I think the impact is going to be felt Io years from now, 20 years from now, when the young people that we are training and the young PIs [principal investigators] that we are funding today become the senior investigators in the country. I truly believe they will have a much different approach to health research that will lead the world." - Wayne Kondro, CMAJ

DOI:I0.1503/cmaj.071276 